\title{
Hydrological Design of Nonstationary Flood Extremes and Durations in Wujiang River, South China: Changing Properties, Causes, and Impacts
}

\author{
Xiaohong Chen, ${ }^{1,2}$ Lijuan Zhang, ${ }^{1,2}$ C.-Y. Xu, ${ }^{3,4}$ Jiaming Zhang, ${ }^{1,2}$ and Changqing Ye \\ ${ }^{1}$ Department of Water Resources and Environment, Sun Yat-sen University, Guangzhou 510275, China \\ ${ }^{2}$ Key Laboratory of Water Cycle and Water Security in Southern China of Guangdong High Education Institute, \\ Sun Yat-sen University, Guangzhou 510275, China \\ ${ }^{3}$ Department of Earth Sciences, Uppsala University, 75236 Uppsala, Sweden \\ ${ }^{4}$ Department of Geosciences, University of Oslo, 0316 Oslo, Norway
}

Correspondence should be addressed to Changqing Ye; yechangqing2001@hotmail.com

Received 12 February 2013; Accepted 7 May 2013

Academic Editor: Guohe Huang

Copyright (c) 2013 Xiaohong Chen et al. This is an open access article distributed under the Creative Commons Attribution License, which permits unrestricted use, distribution, and reproduction in any medium, provided the original work is properly cited.

The flood-duration-frequency (QDF) analysis is performed using annual maximum streamflow series of 1-10 day durations observed at Pingshi and Lishi stations in southern China. The trends and change point of annual maximum flood flow and flood duration are also investigated by statistical tests. The results indicate that (1) the annual maximum flood flow only has a marginally increasing trend, whereas the flood duration exhibits a significant decreasing trend at the 0.10 significant level. The change point for the annual maximum flood flow series was found in 1991 and after which the mean maximum flood flow increased by $45.26 \%$. (2) The period after 1991 is characterized by frequent and shorter duration floods due to increased rainstorm. However, land use change in the basin was found intensifying the increased tendency of annual maximum flow after 1991. And (3) under nonstationary environmental conditions, alternative definitions of return period should be adapted. The impacts on curve fitting of flood series showed an overall change of upper tail from "gentle" to "steep", and the design flood magnitude became larger. Therefore, a nonstationary frequency analysis taking account of change point in the data series is highly recommended for future studies.

\section{Introduction}

Inadequate understanding of the probabilistic behaviour of extreme flows when designing a hydraulic structure may have significant economical impacts on the design values of hydraulic projects [1-5]. Indeed, flood severity can best be characterized by its magnitude and duration. Thus, both of these characteristics need to be studied together. Moreover, the stationarity assumption has long been compromised by human disturbances in river basins, especially for the floods' volume and duration. The accuracy of design flood will be affected if the parameter change is not considered for flood frequency analysis. Designed by the existing engineering hydrologic analysis method, basin development and utilization project, flood control, antidrought projects, and operation dispatches will face the risk of distortion in design frequency caused by the ever-changing environment.

When refer to floods' volume and duration, two different approaches can be utilised: the peak-volume analysis and the QDF analysis [1]. It is important to mention that in the peak-volume analysis approach the determination of the flood event's starting and ending dates contains a part of subjectivity [1]. QDF models are extensions of standard flood frequency models, which summarize the frequency of flood events for different flood probabilities and durations by one compound formula [6]. There have been numerous studies 
in the past on QDF approach, a few of which are discussed below. The work on QDF was initiated almost four decades ago [7]. In the $1990 \mathrm{~s}$, Sherwood [8] and Balocki and Burges [9], among others, laid out the basis of the present form of the QDF model. Javelle et al. [1] successfully used converging approach to the QDF modeling based on the assumption of the convergence of different flood distributions for small return periods in Canada. This approach has been successfully applied in many areas around the world. such as Martinique, France, Burkina Faso, and Romania [6, 10-12].

Nevertheless, recent studies on stationarity of hydrologic records conducted in different parts of the world have identified significant changes in the statistical parameters of the analyzed records [6]. Many studies in meteorology and hydrology still do not attempt to detect the variability in this parameter. In fact, the effect of changes in variability in the detection of usual trends in average flood is only poorly understood [13]. After the nonstationarity of flood series is generated, the statistical properties of data samples (such as mean and standard deviation) and distribution curves change over time, and the uncertainties of exceedance probability and the corresponding design flow will also change [14]. A summary of non-stationary flood frequency analysis methods is provided in Kailaq [15]. Aiming at studying the nonstationarity of hydrologic statistical characteristics in the changing environment, the non-stationary series based on time-varying statistical parameters can be established. A frequency analysis model of non-stationary extreme value series was proposed by Strupczewski et al. [14], which embedded the trend component into the distribution of first- and second-order moments (time-varying moments, TVM); that is, the trends of mean and variance of statistical parameters were considered. The distribution function of the model is described through first and second moments, and thus the design flow can be obtained considering changes in time. TVM approach has been successfully applied in many areas around the world. Based on the same principle of TVM model, Vogel et al. [16] showed that the flood magnitude in many regions of the USA had an increasing trend, and floods with return periods of 100 years might become more common in some basins. Villarini [17] found that the design flow of 100-year flood calculated on a basis of traditional frequency analysis method changes over time. The study conducted by Strupczewski et al. [14] in analyzing the nonstationary hydrologic extreme value series showed that the function relationship can be established between the design flow $x_{P}$, design level $P$, and time $t$ as $x_{P}=F(p, t)$. Therefore, under a certain design level $P$, the design flow $x_{P}$ changes over time $t$.

The QDF models cited above reveal that changing environmental conditions call for further studies that can take into account the non-stationary character of hydrologic records and that can deal with time-dependent parameters of flood frequency distributions [6]. There are only a few studies focusing on QDF models applicable to non-stationary conditions in the recent hydrologic literature. Cunderlik and Ouarda [6] defined the key concepts of a non-stationary approach to regional QDF modelling from a hydrologically homogeneous region in Quebec. The approach refers to the
TVM model proposed by Strupczewski et al. [14], based on the assumption of nonstationarity of the first two moments of the series. The case study results demonstrate that ignoring statistically significant nonstationarity of hydrologic records can seriously bias flood quantiles estimated for the near future.

Indeed, the nonstationarity of a flood series is not only defined by the variation of trend, but also by sudden changes. The TVM non-stationary model is only suitable for nonstationary flood series which have trend of variation [14]. While several books and articles in scientific journals use non-stationary QDF models for probability distributions with variation of trend, less study has been published in the hydrologic literature about non-stationary QDF analysis for sudden changes. This is a difficult task due to the problems in selecting the best non-stationary processing approach from the candidate flood frequency analysis methods available in the literature.

Due to the changes in meteorological variables (such as rainfall and evaporation) and human activities (such as land cover changes) in the Wujiang River basin, the runoff generation conditions and statistical properties of flood series samples (such as mean and standard deviation) have changed and shown the nonstationarity of the series prior and posterior to the change point. The aim of this research is to develop a statistical model that provides a more complete description of a basin's flood regime that can be used to (1) explore the changing characteristics and impact mechanism of design value for non-stationary hydrologic extreme flow with abrupt jumping change point and (2) investigate possible causes behind changes of hydrological extremes. The study gives an implication of the impact of climate/landuse change on flood occurrences and magnitudes. The findings from this study will benefit hazard mitigation under the influences of changing climate and intensifying human activities in the Wujiang basin and other basins in the world.

\section{Methodology}

2.1. Flood Frequency Distribution. Many probability distributions (PDs) have been considered, in different situations, for the probabilistic modeling of extreme events, including the Pearson type III (P3), log-Pearson III (LP3), two-parameter lognormal (LN2), three-parameter lognormal (LN3), Gumbel (extreme value type I, EV1), Weibull (extreme value type III), general extreme value (GEV), and generalized logistic distribution, (GLO). Rao and Hamed [18] and Reiss and Thomas [19] provide details of these probability density functions. Two of them are light-tailed distributions (P3, Weibull), four of them are mixed-tailed distributions (GEV, Gumbel, LN3, and LN2), and the other two are heavy-tailed distributions (GLO and LP3). These distributions have been selected because they are all currently in use in various regions.

2.2. Nonstationarity of Flood Series Detection. Cumulative curve method is often used to evaluate details on temporal variability of hydrological time series. Cumulative curve method was first proposed by Hurst [20] and used to reveal 
the changes of reservoir capacity in Nile River. In this study, the Cumulative Sum of Departures of Modulus Coefficient (CSDMC) was used to detect the phase change characteristics of annual maximum flood flow. CSDMC method can be expressed by the following equations [21]:

$$
\begin{gathered}
R_{i}=\frac{Q_{i}}{\bar{Q}}, \quad(i=1,2,3, \ldots, N), \\
K_{p}=\sum_{i=1}^{p}\left(R_{i}-1\right), \quad(p=1,2,3, \ldots, N),
\end{gathered}
$$

where $i$ indicates the sequence value of time series in $N$ year, $K_{p}$ indicates CSDMC cumulative moment balance value in $1 \sim p$ year, $Q_{i}$ is the annual maximum peak flow, and $\bar{Q}$ indicates the multiyear mean annual maximum flood flow values. The period of $K_{p}$ with a downward trend (negative slope) indicates the time of lower value than average annual maximum flood flow; on the contrary, the period of $K_{p}$ with an upward trend (positive slope) indicates the time of higher value than average annual maximum flood flow [21].

Cumulative sum (CUSUM) charts are used for abrupt change point detection in climate series. Each significant change in the direction of CUSUM indicates a sudden fluctuation of mean. CUSUM chart with a relatively straight route indicates basically no changes in flow mean in this period.

2.3. QDF Model. The aim of the QDF modelling is to provide a continuous formulation of flood quantiles, $Q(d, T)$, as a function of probability, $T$, and duration, $d[6]$. An instantaneous streamflow time series can be used to characterise each observed flood by its instantaneous peak flow, $Q(t)$, and by the values of mean streamflows for given durations, $Q_{d}(t)$, using a moving average technique. The method is based on a moving average with a window length $d$ over the time series $Q(t)$. From the series $Q_{d}(t)$, annual maximum values, $Q_{d}^{\max }(t)$, can be extracted as

$$
Q_{d}^{\max }(t)=\max _{t^{-} \leq t \leq t^{+}}\left\{Q_{d}(t)\right\}
$$

where $t^{-}$and $t^{+}$are the first and last days of the $t$ th water year or calendar year. A set of $Q_{d}^{\max }(t)$ series, derived for different durations $d$, is then used to relate flood quantiles to the return period and flood duration [6].

Javelle et al. [1] defined a stationary at-site QDF model based on the following two assumptions. The first is the flood distributions which are self-affine along a horizontal line of equation. The second is that for a given return period the evolution of the quantile $Q(d, T)$ as a function of $d$ can be described by a hyperbolic form. In these conditions the QDF model can be written as follows:

$$
Q(d, T)=\frac{Q_{0}(d=0, T)}{1+d / \Delta}
$$

where $Q_{0}(d=0, T)$ is the distribution corresponding to instantaneous peak discharges, $d$ is the duration of flood, and $\Delta$ is a parameter describing the shape of the hyperbolic form, which can be related to flood dynamics [1]. A large value of $\Delta$ often indicates a slow flood while a small value of $\Delta$ implies flash floods. Consequently parameter $\Delta$ can be considered as a characteristic flood duration for the basin.

Equation (3) reveals that each distribution $Q(d, T)$ multiplied by $1+d / \Delta$ is equal to the $Q_{0}(d=0, T)$ distribution. This property can be used to estimate parameter $\Delta$. The annual maximum streamflow series $Q_{d}^{\max }(t)$ is first scaled:

$$
q_{d}^{\max }(t)=Q_{d}^{\max }(t)\left[1+\frac{d}{\delta}\right]
$$

The characteristic duration $\Delta(t)$ at a time $t$ is selected as the optimum value $\delta^{\text {opt }}$ that minimizes the dispersion $\varepsilon$ of the experimental time-scaled values, $q_{d}^{\max }(t)$

$$
\begin{gathered}
\Delta=\delta^{\mathrm{opt}}, \\
\varepsilon=\min \left\{\frac{1}{N} \frac{1}{D} \sum_{i=1}^{N} \sum_{j=1}^{D}\left[\frac{q_{d_{j}}^{\max }(i)-\bar{q}_{d}(i)}{\bar{q}_{d}(i)}\right]^{2}\right\},
\end{gathered}
$$

where $\bar{q}_{d}(t)$ is the mean scaled value calculated for $D$ durations $d_{j}$ and $N$ is the record length. Parameters of the distribution $Q_{0}(d=0, T)$ are estimated by fitting a distribution function to the series $\bar{q}_{d}(t)[6]$.

\section{Study Area and Data}

Wujiang River is one of the branches of the Pearl River in South China, with the latitude ranging from $24^{\circ} 46^{\prime}$ to $25^{\circ} 41^{\prime} \mathrm{N}$ and the longitude ranging from $112^{\circ} 23^{\prime}$ to $113^{\circ} 36^{\prime} \mathrm{E}$ (Figure 1). The climate is dominated by the southwest and southeast Asia monsoons in summer, leading to comparatively high humidity and uneven distribution of precipitation through the season.

The main gauging stations, named Pingshi and Lishi, and the recorded lengths of the data are given in Table 1. The observed flood discharge series at each station is visually investigated to see if there are apparent trends or jumps. Statistical tests including the Mann-Kendall (M-K) test for trend are conducted $[22,23]$, from which it can be seen that there is no statistically significant trend for annual maximum daily discharges. The autocorrelation coefficient and randomness test indicate that hydrological sequences satisfy independent assumption. The precipitation time series data used in this study are collected from National Meteorological Information Center in China (Table 1).

\section{Results}

4.1. Nonstationarity of Flood Series Detection. It was found that annual maximum flood flow of short durations (1-5 days) exhibited stronger positive slopes and those of long durations ( $>5$ days) exhibited moderately positive slopes. The annual maximum flood flow of Pingshi and Lishi stations showed a change process as "steady decline to significant rise" (Figure 2). The deluge events frequently occurred after 1990 , basically concentrated in the last 20 years of the time series. CSDMC test was used to identify change point 


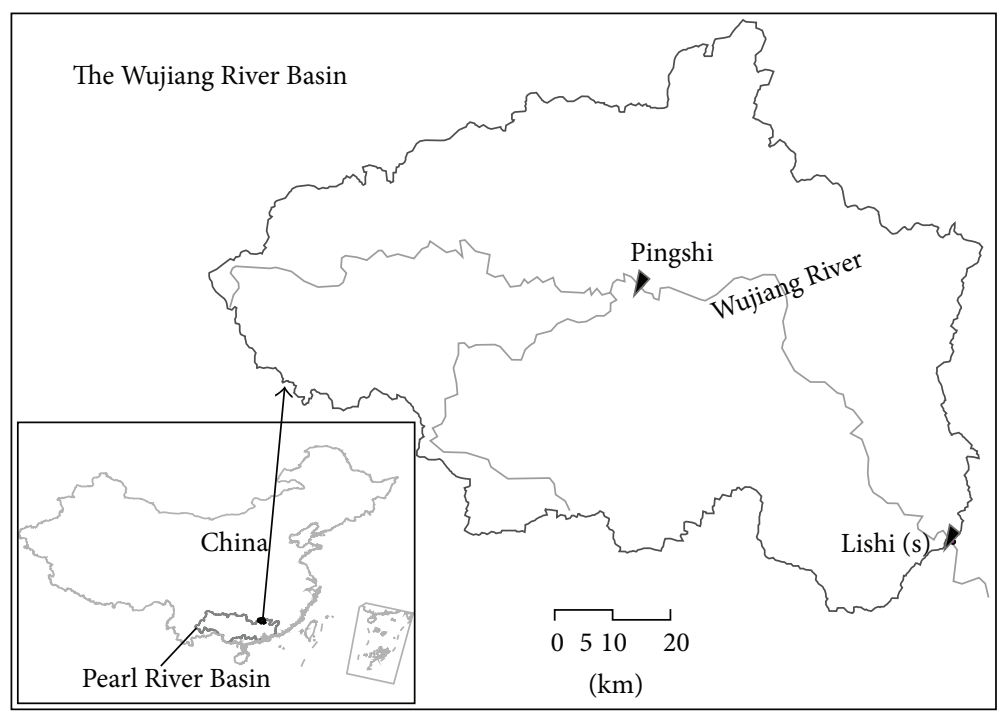

Streamflow gauges

Figure 1: Location of the Wujiang River, the hydrological stations within the Wujiang River basin.

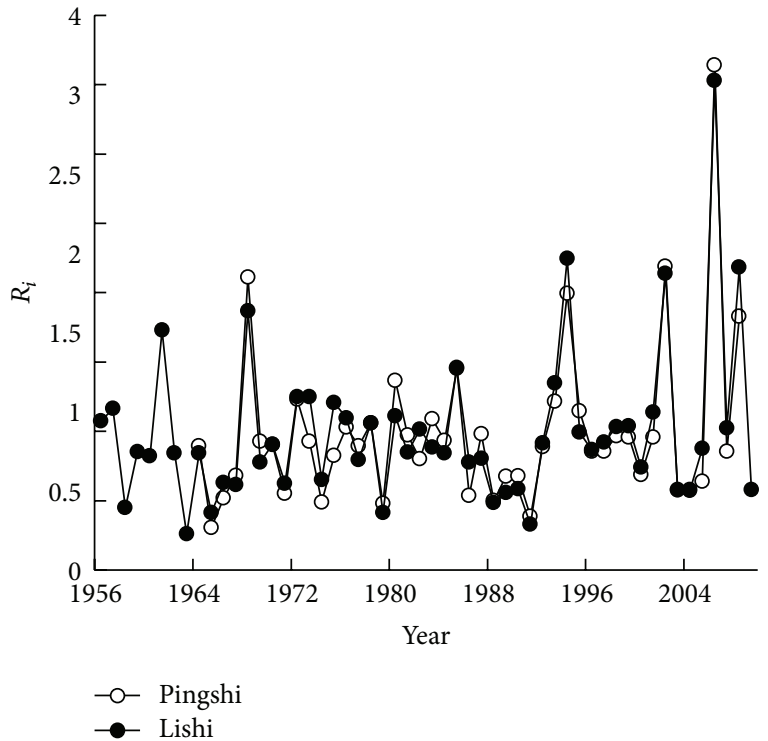

(a)

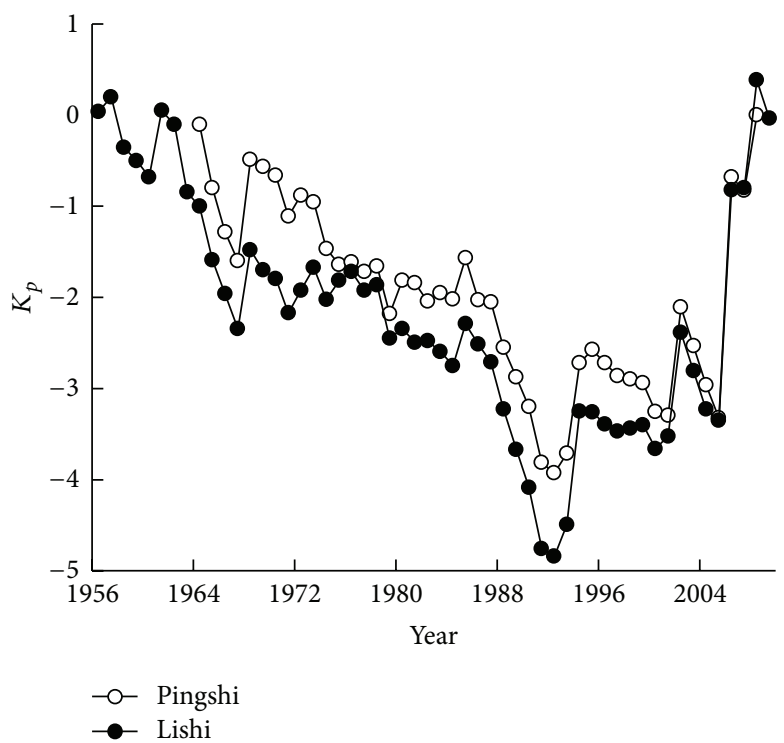

(b)

Figure 2: Change process (a) and Cumulative Sum of Departures of Modulus Coefficient test (b) of annual maximum flood flow series in Wujiang River.

and nonstationarity of series [15]. As shown in Figure 2, the change point appeared in 1991. Specifically, the annual maximum flood flow had a significant upward trend from 1991 to 2009.

4.2. Selection of Probability Distribution Function. Akaike information criterion (AIC) was taken as the discrimination criterion of the optimal model [24]. As viewed from the AIC fitting test values of different distribution curves, GLO model in Wujiang River is the best fitting model (Table 2). Parameter estimations for all the 8 distributions by maximum likelihood estimation (MLE) are given in Table 3. It showed that big floods happened more frequently after 1991, making steeper shape in the left side of the empirical flood distribution. Heavy-tailed GLO owns greater flexibility in terms of description of probability behaviours with great hydrological extremes. The GLO probability distribution function which fits the flood series well will be adopted as the best choice in describing the statistical properties of the flood series.

4.3. Designed Flood Flow Corresponding to Different Return Periods. For illustrative purposes, the flood flow series at the 
TABLE 1: Detailed information on the stream flow gauging stations and rainfall stations.

\begin{tabular}{|c|c|c|c|c|c|c|c|}
\hline Station & Loc & tion & Area $\left(\mathrm{km}^{2}\right)$ & Flow period & Reservoir capacity $\left(10^{8} \mathrm{~m}^{3}\right)$ & Rainfall stations & Rainfall period \\
\hline Pingshi & $113^{\circ} 05^{\prime} \mathrm{E}$ & $25^{\circ} 28^{\prime} \mathrm{N}$ & 3567 & 1964.1.1-2008.12.31 & $<1$ & \multirow{2}{*}{ Sanxi, Lechang, Lishi } & \multirow{2}{*}{ 1955.1.1-2009.12.31 } \\
\hline Lishi & $113^{\circ} 53^{\prime} \mathrm{E}$ & $24^{\circ} 88^{\prime} \mathrm{N}$ & 6976 & 1956.1.1-2009.12.31 & 3.38 & & \\
\hline
\end{tabular}

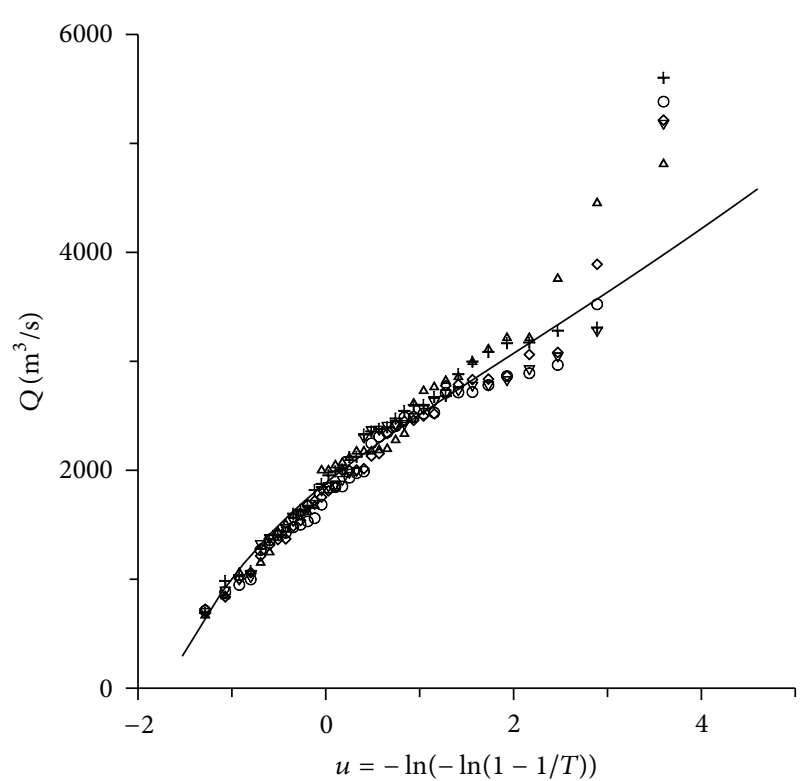
$\Delta d=1$
$\diamond d=3$
O $d=5$
$\begin{array}{ll}\nabla & d=7 \\ +\quad & d=9\end{array}$
$-\mathrm{Q}(d=0, T) \_\mathrm{GLO}$

(a)

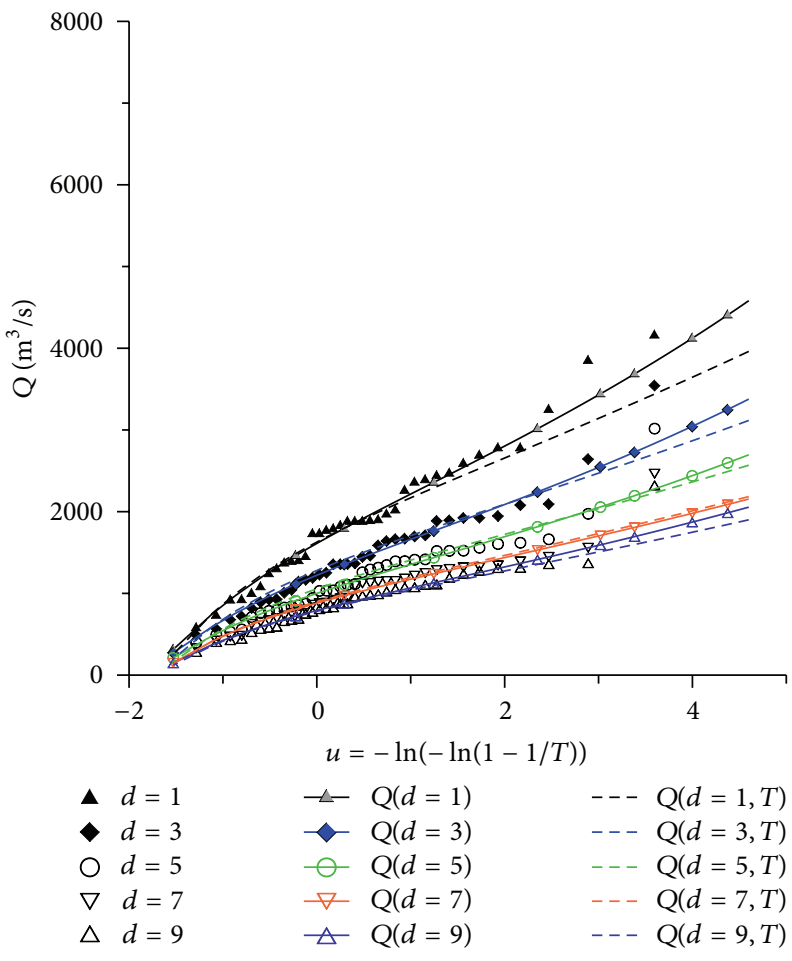

(c)

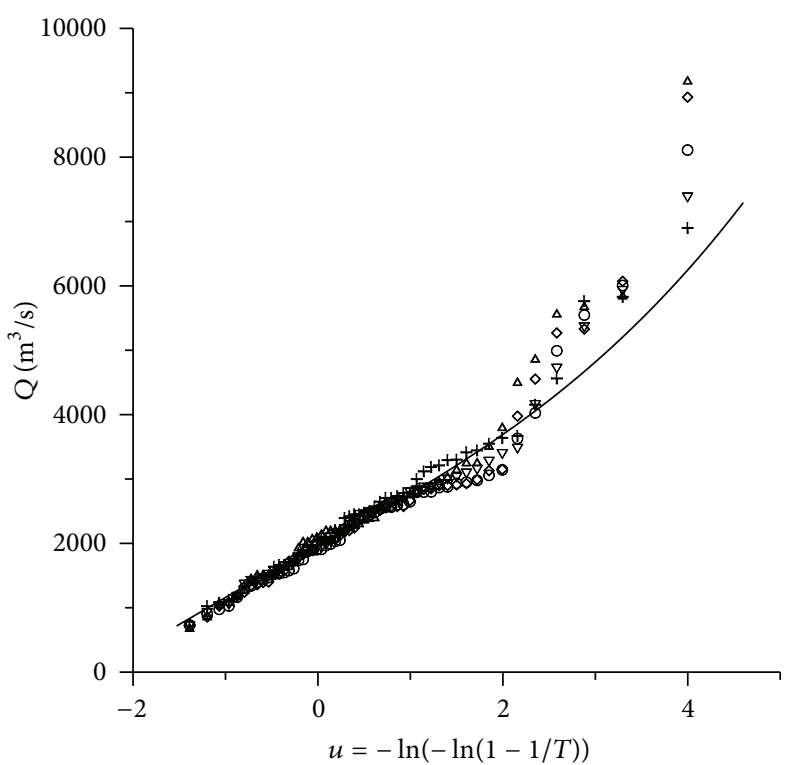
$\Delta d=1$
$\nabla \quad d=7$
$\diamond d=3$
$+\quad d=9$
$\bigcirc d=5$
- $Q(d=0, T)_{-}$GLO

(b)

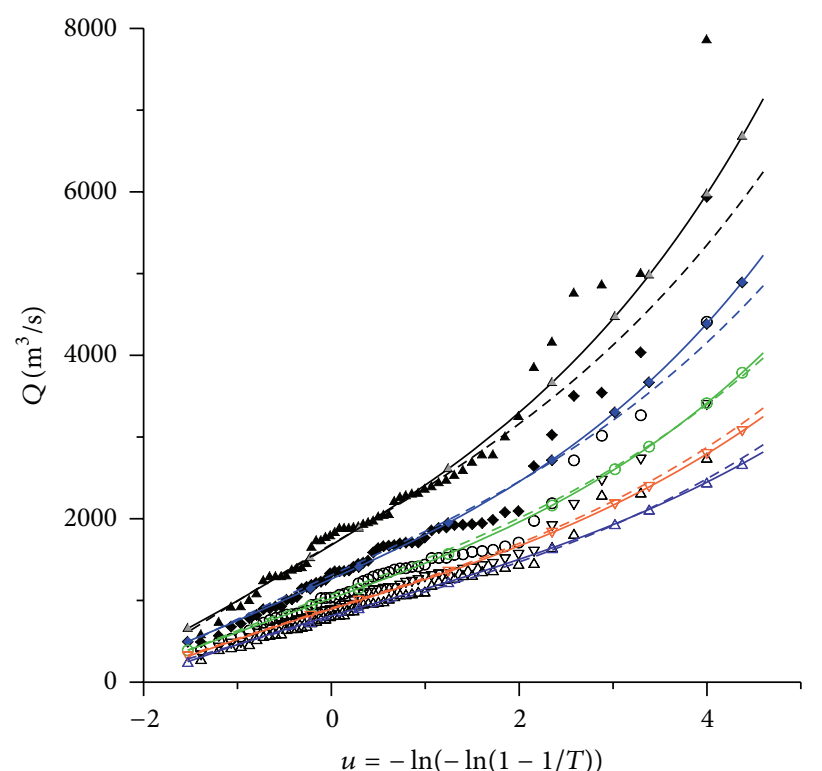

A $d=1$

- $d=3$

○ $d=5$

$\nabla d=7$

$\triangle d=9$

$\neg \mathrm{Q}(d=1)$
$\neg \mathrm{Q}(d=3)$
$\nabla \mathrm{Q}(d=5)$
$\nabla \mathrm{Q}(d=7)$
$\triangle \mathrm{Q}(d=9)$

(d)

FIGURE 3: QDF growth curves at Lishi station in 1956-1991 (left) and in 1956-2009 (right). 


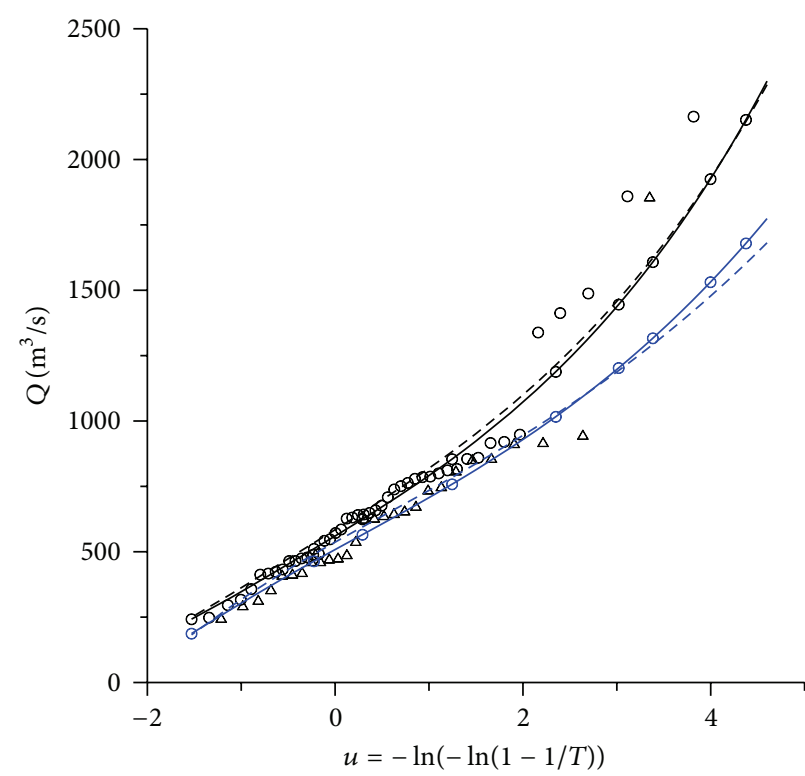

$\triangle d=5(1964-1991)$

O $d=5(1964-2008)$

- $Q(d=5) \_1964-1991$

(a)

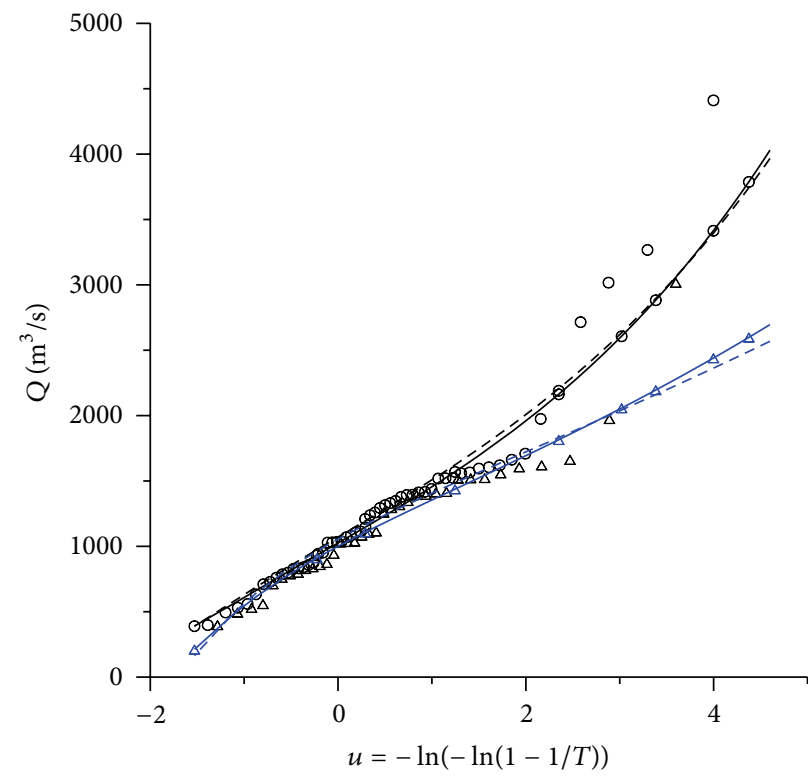

$\triangle \quad d=5(1956-1991)$

O $d=5$ (1956-2009)

$\triangle Q(d=5) \_1956-1991$

$\frown \mathrm{Q}(d=5) \_1956-2009$

- - $Q(d=5, T) \_1956-1991$

- - $Q(d=5, T) \_1956-2009$

(b)

FIGURE 4: QDF growth curves for duration $d=5$ days, $Q_{T}(d=5)$, at Pingshi station (a) and Lishi station (b).

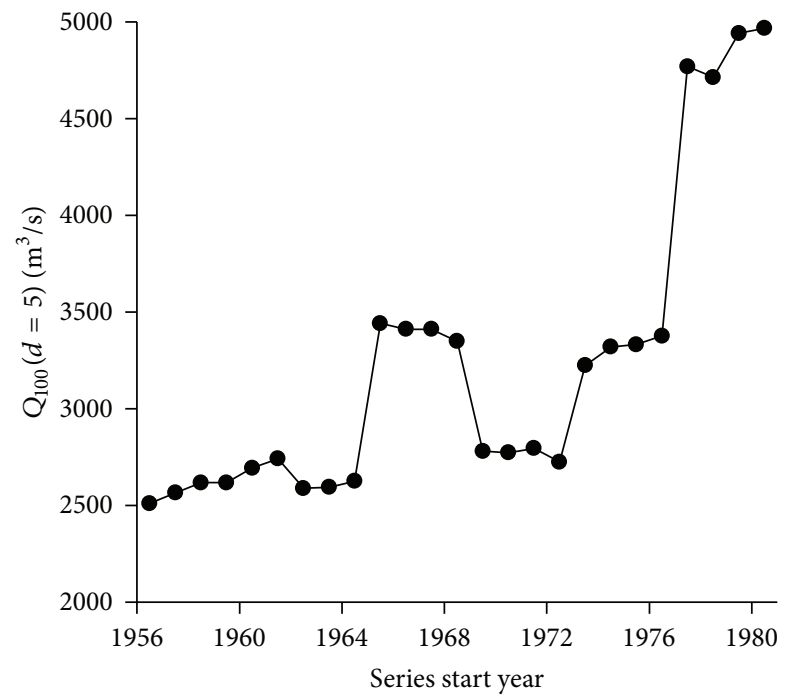

(a)

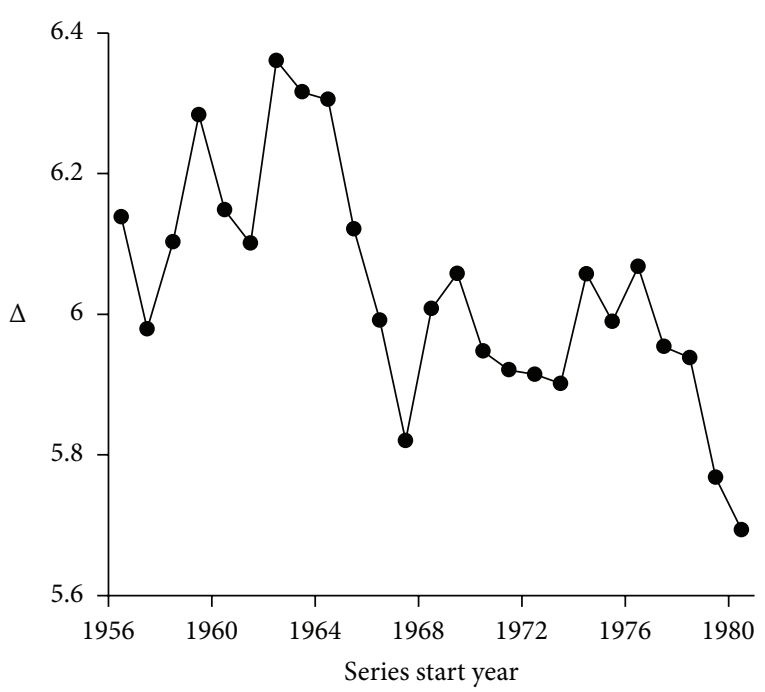

(b)

FIGURE 5: Change process of 100-year flood quantiles for duration $d=5$ days, $Q_{100}(d=5)$ (a) and parameter $\Delta(\mathrm{b})$ at Lishi station.

TABLE 2: AIC fitting test values of 8 distributions for flood frequency analysis in Wujiang River.

\begin{tabular}{lcccccccc}
\hline Station & P3 & GLO & GEV & Weibull & GUM & LN3 & LN2 & LP3 \\
\hline Pingshi & 716.96 & $\mathbf{6 9 6 . 3 8}$ & 697.57 & 702.07 & 701.27 & 730.21 & 697.06 & 697.77 \\
Lishi & 917.61 & $\mathbf{9 1 3 . 3 2}$ & 915.40 & 920.24 & 916.25 & 924.79 & 913.52 & 915.36 \\
\hline
\end{tabular}




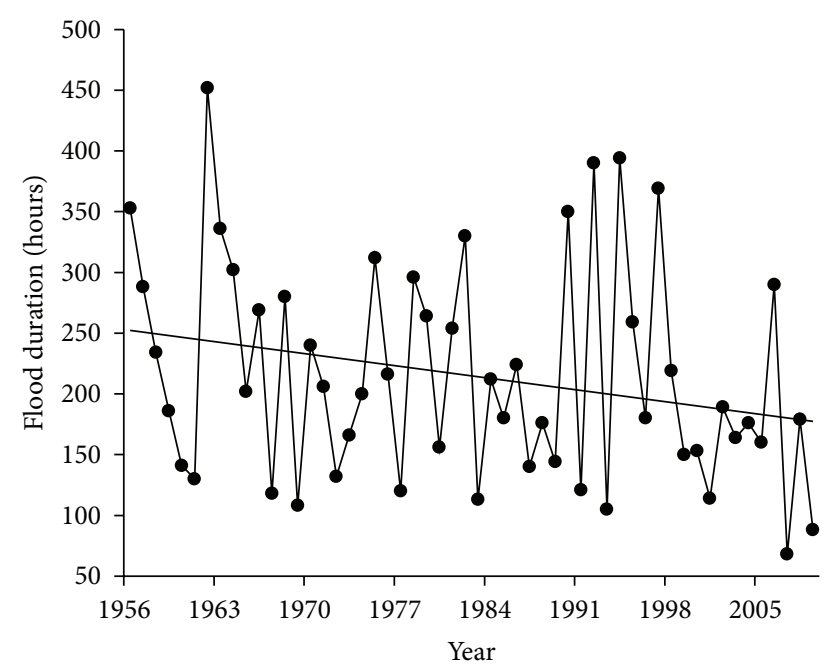

FIGURE 6: Original flood duration series at Lishi station in Wujiang River basin.

TABle 3: Parameter estimation of optimal distribution model in Wujiang River (MLE).

\begin{tabular}{lccccc}
\hline \multirow{2}{*}{ Station } & \multirow{2}{*}{ Flow period } & \multirow{2}{*}{ PD } & \multicolumn{3}{c}{ Parameters } \\
& & & Scale & Shape & Location \\
\hline Pingshi & $1964 \sim 2008$ & GLO & 286.412 & -0.346 & 1085.513 \\
Lishi & $1956 \sim 2009$ & GLO & 512.532 & -0.303 & 1940.168 \\
\hline
\end{tabular}

Lishi station is used to demonstrate the study procedure and the results (Figure 3 ). In the first step, the first 36 years of the data (1956-1991) of the total observation period (19562009) were analyzed. In the second step of the analysis, the procedure was repeated using the data from the whole 54year-long observation period 1956-2009. The results from both periods were then compared (Figure 3).

Figure 4 compares the QDF growth curves estimated for different time horizon by means of the stationary QDF methods for the 5-day duration, $Q_{T}(d=5)$, at Pingshi and Lishi stations. The change characters of optimal linear frequency distribution at the Pingshi and Lishi stations before and after change point of flood flow are compared. The impacts on the fitted curve of flood series showed an overall upper tail from "gentle" to "steep," meaning that the design flood magnitude will become larger.

It can be seen from Table 4 that $Q_{T}(d=5)$ values correspond to different return periods before and after the change point. For the same $Q_{T}(d=5)$ value, the return periods at the Pingshi and Lishi stations come to be decreasing after the environment changed. Return periods of these stream flow events are about 25 years and could be more than 100 years before the change point, showing tremendous influences of changing environment on flood changes. After changes in the hydrological regime, the flood return period estimated before the change is often unable to well describe the flood frequency characteristics after environmental changes.
4.4. The Changes of Flood Duration Parameter Impact to the Designed Flood Flow. To further understand the flood frequency characteristics, the moving samples of finite length (30 years) were analysed, and it can be observed that variance and low-frequency quantiles, particularly of short-duration flood, are generally an increasing function of time. Taking Lishi station as a case study, the change process of $Q_{100}(d=$ $5)$ values corresponding to return periods of 100 years and parameters of QDF model was obtained (Figure 5). For the same design level $P$, the design value significantly altered over time. In this case, the TVM non-stationary model cannot catch the jumping of point for non-stationary flood series resulting in the distortion risk in design frequency.

On the contrary the parameter $\Delta$ shows a significant decreasing trend (Figure 5). Other parameters of the QDF model have demonstrated similar behavior with significant alterations over time. The impacts of parameters on distribution curve showed an overall performance as upper tail from "gentle" to "steep" (Figure 3), and the design flood magnitude will become larger. Generally, the original flood duration of Lishi Station in Wujiang River has a decreasing trend at the $10 \%$ significant level during the period from 1956 to 2009 (Figure 6). The trend of original flood duration is identical with the change process of parameter $\Delta$ using moving samples of finite length (30-year). Therefore, the change of flood duration is the main factor leading to the change of design flow by QDF model.

\section{Discussions}

It would be more important to investigate possible causes behind changes of hydrological extremes after 1990s, which can be attributed to the impact of climate change and human activities.

5.1. Relationship between Flood Flow and Precipitation. As the rainfall is the primary source of stream flow, we investigated the possible relationship between annual maximum stream flow and corresponding basin rainfall. After 1990s, the total precipitation amount and frequency of rainstorms in the Wujiang River basin are in evidently increasing tendency (Figure 7). On the contrary, the duration of precipitation is in slightly decreasing tendency, indicating that after 1990s, both the amount and intensity of precipitation are in evidently increasing tendency (Figure 7). The 1990s are characterized by highly frequent floods due to increased rainstorm in this time interval. Therefore, spatiotemporal distribution of precipitation changes and rainstorm is still the major cause behind the occurrence of flood events in the region.

5.2. Relationship between Flood Flow and Human Influences. To a certain extent, changes in annual runoff coefficient reflect human influences on the relationship of rainfall and runoff in the basin. CSDMC test was used to identify nonstationarity and change point of annual runoff coefficient in the Wujiang River. The change point of annual runoff coefficient is found in 1991. To better understand the possible relationship between the annual maximum flood flow and land cover, we also collected the land cover information during 


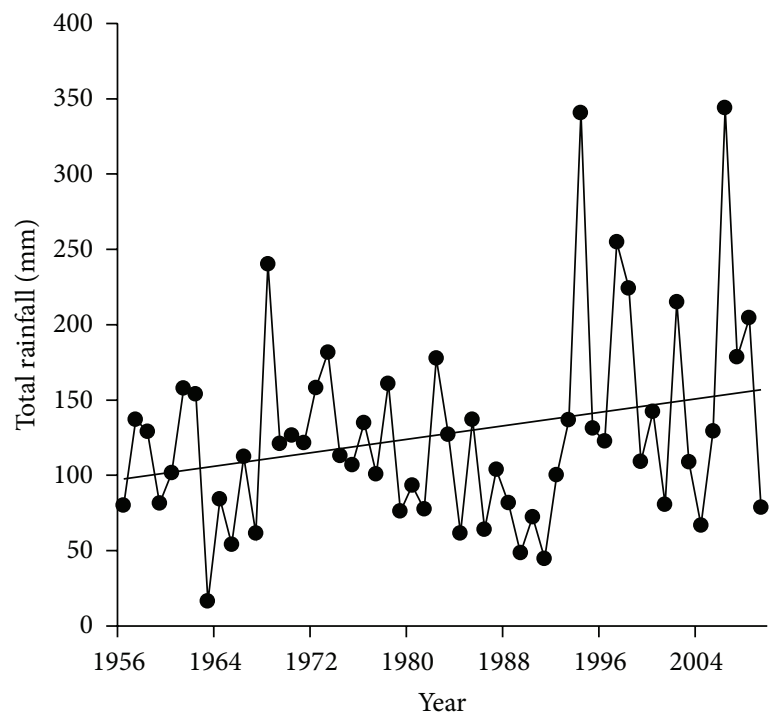

(a)

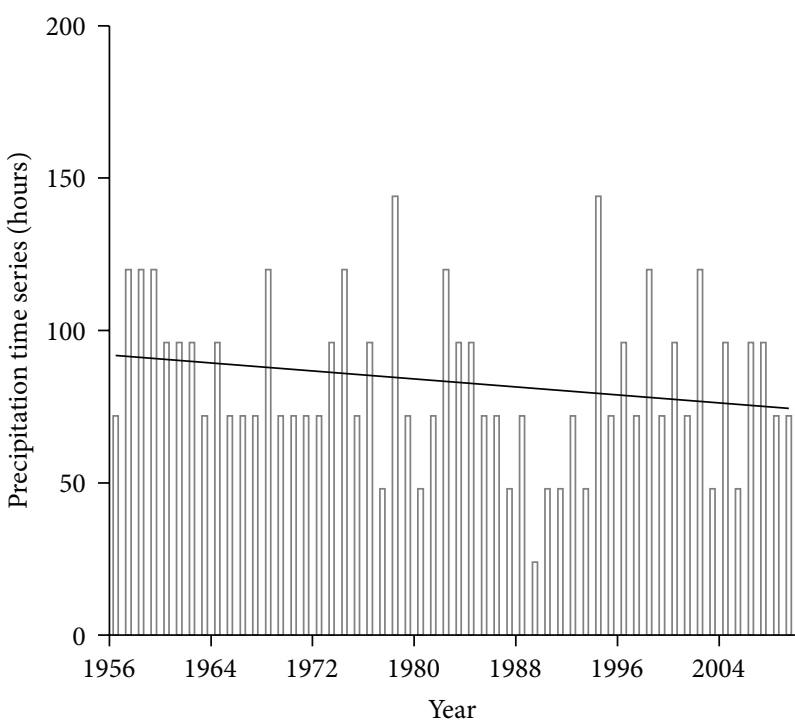

(b)

FIGURE 7: Change process of the corresponding basin rainfall of flood flow (a) and rainfall durations (b) in Wujiang River.

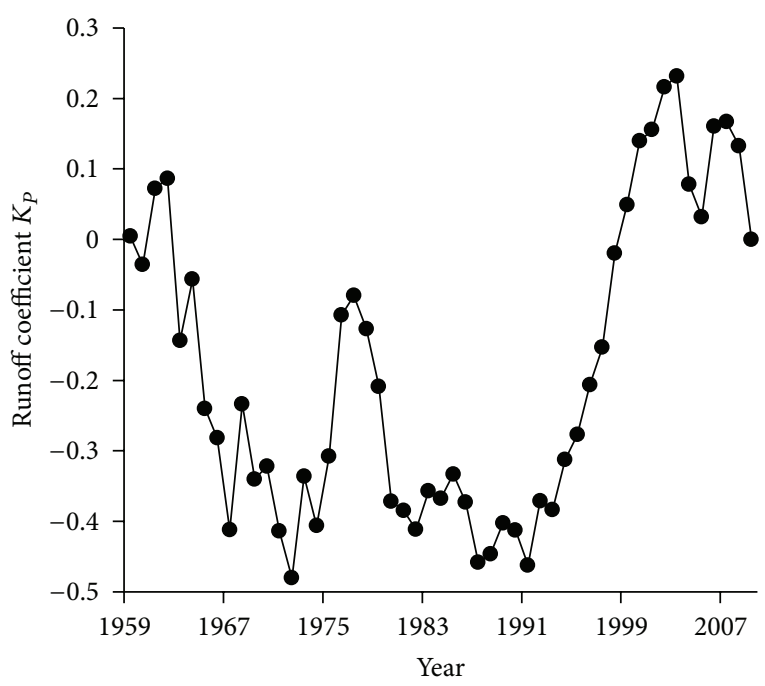

(a)

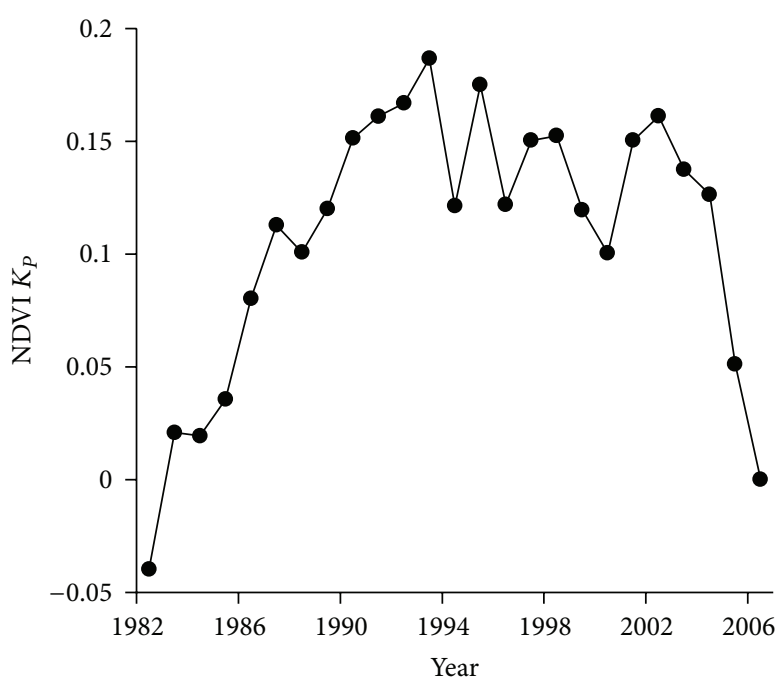

(b)

Figure 8: Cumulative Sum of Departures of Modulus Coefficient test of annual runoff coefficient (a) and NDVI (b) series in Wujiang River.

1981-2006 (Normalized Difference Vegetation Index: NDVI) (Figure 8). NDVI reflects the overall information for the ground vegetation. The data are from Global Inventory Modeling and Mapping Studies [25]. Note that the ground vegetation has a decreasing trend and with a change point in 1991 (see Figure 8), causing more quick flow and therefore strengthening flood events. So, land use change can be attributed as another reason affecting extreme hydrological events.

With the aim to explore impacts of water conservancy regulation on hydrological extremes, detailed information about water conservancy was collected. There are few reservoirs in the Wujiang River basin, and majority of which are mainly for agricultural irrigation, rather than for flood control. Furthermore, most water reservoirs were built along the tributaries, which greatly limits the flood control function of the water reservoirs. Thus, the flood control effects of the water reservoirs are not evident in general sense in this catchment. In the study conducted by Miller et al. [26] for 17 river basins in the UK, it is shown that the lakes have had a considerable impact on estimates of flood frequency and associated uncertainty.

Increasing meteorological extremes and enhancing precipitation intensity due to altered hydrological cycle may have 
TABLE 4: Designed maximum flood flow $Q(d=5)\left(\mathrm{m}^{3} / \mathrm{s}\right)$ and related return periods before and after environment change in Wujiang River.

\begin{tabular}{lcccccccc}
\hline Station & Distribution & Length of series & $T=5$ & $T=10$ & $T=25$ & $T=50$ & $T=70$ & $T=100$ \\
\hline \multirow{2}{*}{ Pingshi } & \multirow{2}{*}{ GLO } & $1964 \sim 1991$ & 836.75 & 1001.95 & 1241.19 & 1447.35 & 1557.19 & 1681.49 \\
& & $1964 \sim 2008$ & 951.67 & 1180.43 & 1541.16 & 1877.61 & 2065.86 & 2286.11 \\
\multirow{2}{*}{ Lishi } & \multirow{2}{*}{ GLO } & $1956 \sim 1991$ & 1566.15 & 1800.44 & 2100.47 & 2330.89 & 2445.16 & 2568.42 \\
& & $1956 \sim 2009$ & 1746.75 & 2147.87 & 2759.51 & 3312.53 & 3616.06 & 3966.57 \\
\hline
\end{tabular}

the potential to intensify the flood events across the Wujiang River basin. Thus, flood control should be enhanced by construction of water reservoirs to reduce the risk of flooding.

\section{Conclusions}

In this study, extremes events are analysed based on the daily streamflow and peak flood dataset at Pingshi and Lishi hydrological stations using QDF model. Results indicate that GLO distribution is the right choice in the description of probability behaviours of extremes events in the Wujiang River basin. Besides, trends and change point of annual maximum flood flow and flood duration are investigated by statistical testing methods including the $\mathrm{M}-\mathrm{K}$ test and the CSDMC technique.

From the trend analysis, it was found that the annual maximum flood flow only had marginally increasing trend, whereas the flood duration exhibited a decreasing trend at the $10 \%$ significant level. The change point for the annual maximum flood flow series was found in year 1991, and after which the mean maximum flood flow increased by $45.26 \%$.

The 1990s are characterized by more frequent floods due to increased rainstorm in this time interval. Vegetation reduction in the basin magnified the increasing tendency of annual maximum flow for the period.

Due to the change of hydrologic regimes the flood return period estimated from data series before the change point does not apply properly to the period after the change point. The impacts on curve fitting of flood series showed an overall performance as upper tail from "gentle" to "steep," and the design flood magnitude will become larger. Therefore, nonstationary frequency analysis for the series with sudden change point is highly recommended for future studies.

Higher probability of floods will lead to serious challenges for flood control. More efforts should be paid to enhance human mitigation to floods in the Wujiang River basin.

\section{Acknowledgments}

The research is financially supported by the National Natural Science Foundation of China (Grants nos. 51210013, 50839005, and 51190091), the Public Welfare Project of Ministry of Water Resources (Grants nos. 201201094, 20130100202 ), and the project from Guangdong Science and Technology Department (Grant no. 2010B050300010), the project from Guangdong Water Resources Department (Grant no. 2009-39). A collaborative contribution by the CSIRO Computation and Simulation Sciences Transformational Capability Platform is also acknowledged.

\section{References}

[1] P. Javelle, T. B. M. J. Ouarda, M. Lang, B. Bobée, G. Galéa, and J. M. Grésillon, "Development of regional flood-durationfrequency curves based on the index-flood method," Journal of Hydrology, vol. 258, no. 1-4, pp. 249-259, 2002.

[2] L. Brandimarte and G. Di Baldassarre, "Uncertainty in design flood profiles derived by hydraulic modelling," Hydrology Research, vol. 43, no. 6, pp. 753-761, 2012.

[3] D. Faulkner, C. Keef, and J. Martin, "Setting design inflows to hydrodynamic flood models using a dependence model," Hydrology Research, vol. 43, no. 5, pp. 663-674, 2012.

[4] A. I. Vornetti and R. S. Seoane, "Derived flood frequency distribution and sensitivity analysis to variations in model parameters," Hydrology Research, vol. 43, no. 3, pp. 249-261, 2012.

[5] A. Reihan, J. Kriauciuniene, D. Meilutyte-Barauskiene, and T. Kolcova, "Temporal variation of spring flood in rivers of the Baltic States," Hydrology Research, vol. 43, no. 4, pp. 301-314, 2012.

[6] J. M. Cunderlik and T. B. M. J. Ouarda, "Regional floodduration-frequency modeling in the changing environment," Journal of Hydrology, vol. 318, no. 1-4, pp. 276-291, 2006.

[7] NERC, "Estimation of flood volumes over different durations," in Flood Studies Report, vol. 1, chapter 5, pp. 243-264, 1975.

[8] J. M. Sherwood, "Estimation of volume-duration-frequency relations of ungauged small urban streams in Ohio," Water Resources Bulletin, vol. 30, no. 2, pp. 261-269, 1994.

[9] J. B. Balocki and S. J. Burges, "Relationships between n-day flood volumes for infrequent large floods," Journal of Water Resources Planning \& Management, vol. 120, no. 6, pp. 794-818, 1994.

[10] M. Meunier, "Regional flow-duration-frequency model for the tropical island of Martinique," Journal of Hydrology, vol. 247, no. 1-2, pp. 31-53, 2001.

[11] L. Mar, P. Gineste, M. Hamattan, A. Tounkara, L. Tapsoba, and P. Javelle, "Flood-duration-frequency modeling applied to big catchments in Burkina Faso," in Proceedings of the 4th FRIEND International Conference, Cape Town, South Africa, March 2002.

[12] R. Mic, G. Galee a, and P. Javelle, "Floods regionalization of the Cris catchments: application of the converging QDF modeling concept to the Pearson III law," in Proceedings of the Conference of the Danube countries, Bucharest, Romania, September 2002.

[13] J. J. M. Delgado, H. Apel, and B. Merz, "Flood trends and variability in the Mekong river," Hydrology and Earth System Sciences, vol. 14, pp. 407-418, 2010.

[14] W. G. Strupczewski, V. P. Singh, and W. Feluch, "Non-stationary approach to at-site flood frequency modelling I. Maximum likelihood estimation," Journal of Hydrology, vol. 248, no. 1-4, pp. 123-142, 2001. 
[15] M. N. Khaliq, T. B. M. J. Ouarda, J. C. Ondo, P. Gachon, and B. Bobée, "Frequency analysis of a sequence of dependent and/or non-stationary hydro-meteorological observations: a review," Journal of Hydrology, vol. 329, no. 3-4, pp. 534-552, 2006.

[16] R. M. Vogel, C. Yaindl, and M. Walter, "Nonstationarity: flood magnification and recurrence reduction factors in the united states," Journal of the American Water Resources Association, vol. 47, no. 3, pp. 464-474, 2011.

[17] G. Villarini, J. A. Smith, F. Serinaldi, J. Bales, P. D. Bates, and W. F. Krajewski, "Flood frequency analysis for nonstationary annual peak records in an urban drainage basin," Advances in Water Resources, vol. 32, no. 8, pp. 1255-1266, 2009.

[18] A. R. Rao and K. H. Hamed, Flood Frequency Analysis., CRC Press, Boca Raton, Fla, USA, 2000.

[19] R. D. Reiss and M. Thomas, Statistical Analysis of Extreme Values: With Applications to Insurance, Finance, Hydrology and Other Fields, Birkäuser, Boston, Mass, USA, 2001.

[20] H. Hurst, "Long term storage capacity of reservoirs," Transactions of the American Society of Civil Engineers, vol. 116, pp. 770799, 1951.

[21] C. A. McGilchrist and K. D. Woodyer, "Note on a distributionfree CUSUM technique," Technometrics, vol. 17, no. 3, pp. 321325, 1975.

[22] M. G. Kendall, Rank Correlation Methods, Griffin, London, UK, 1975.

[23] H. B. Mann, "Nonparametric tests against trend," Econometrica, vol. 13, pp. 245-259, 1945.

[24] H. Akaike, "A new look at the statistical model identification," IEEE Transactions on Automatic Control, vol. 19, no. 6, pp. 716$722,1974$.

[25] C. J. Tucker, J. E. Pinzon, M. E. Brown et al., "An extended AVHRR 8-km NDVI data set compatible with MODIS and SPOT vegetation NDVI data," International Journal of Remote Sensing, vol. 26, no. 20, pp. 4485-5598, 2005.

[26] J. D. Miller, T. R. Kjeldsen, J. Hannaford, and D. G. Morris, "A hydrological assessment of the November 2009 floods in Cumbria, UK," Hydrology Research, vol. 44, no. 1, pp. 180-197, 2013. 


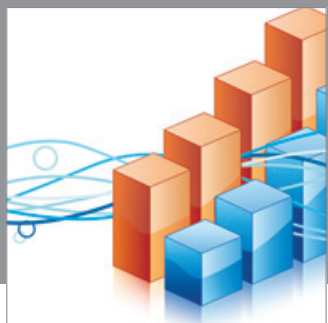

Advances in

Operations Research

mansans

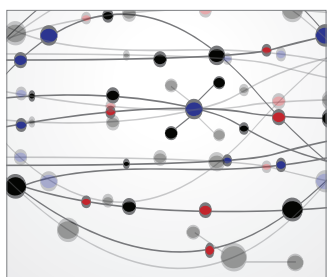

The Scientific World Journal
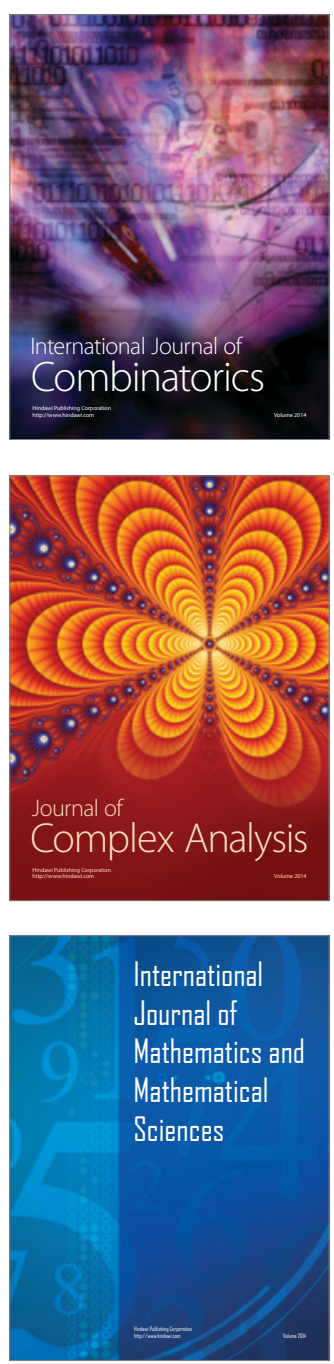
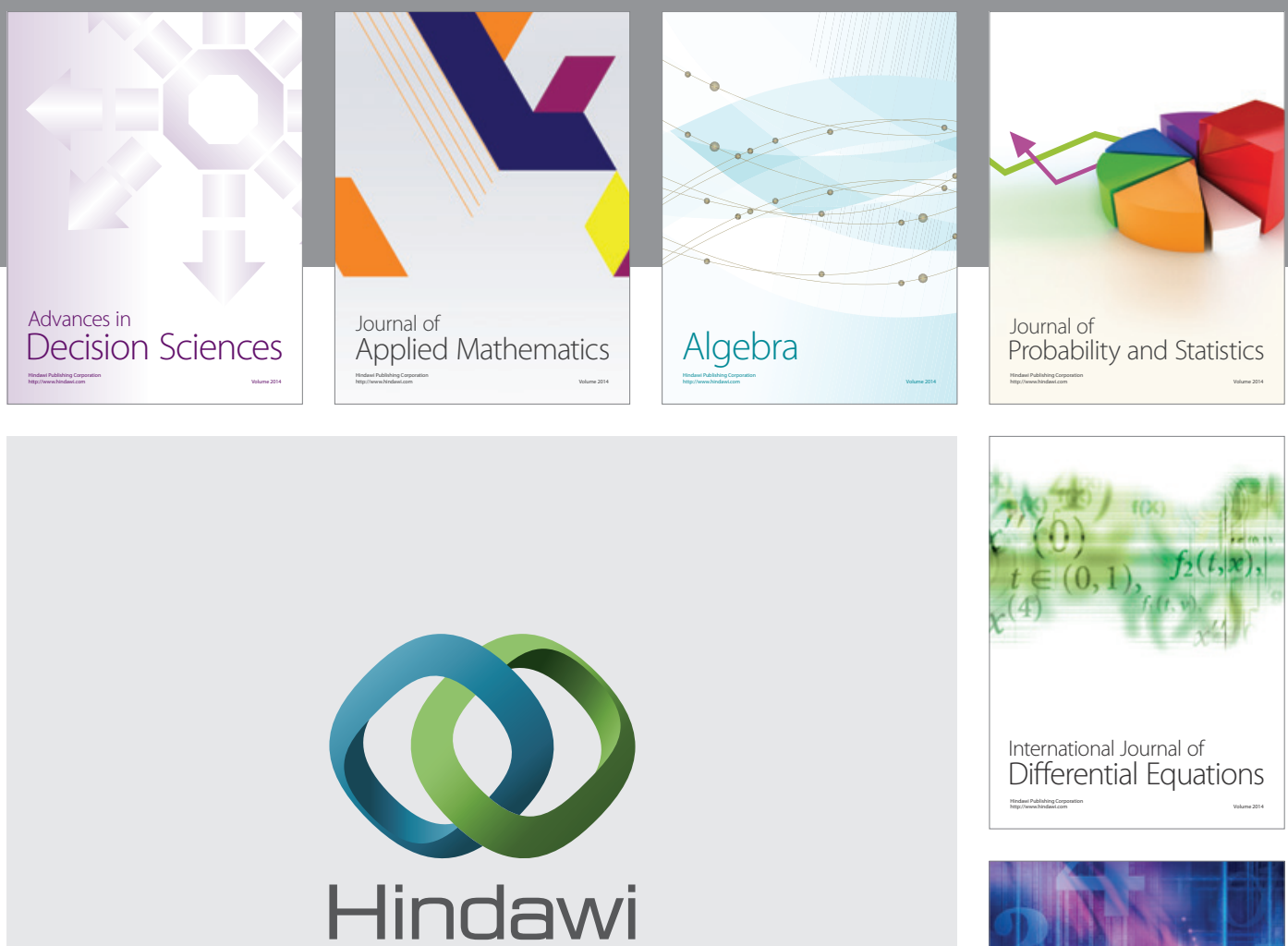

Submit your manuscripts at http://www.hindawi.com
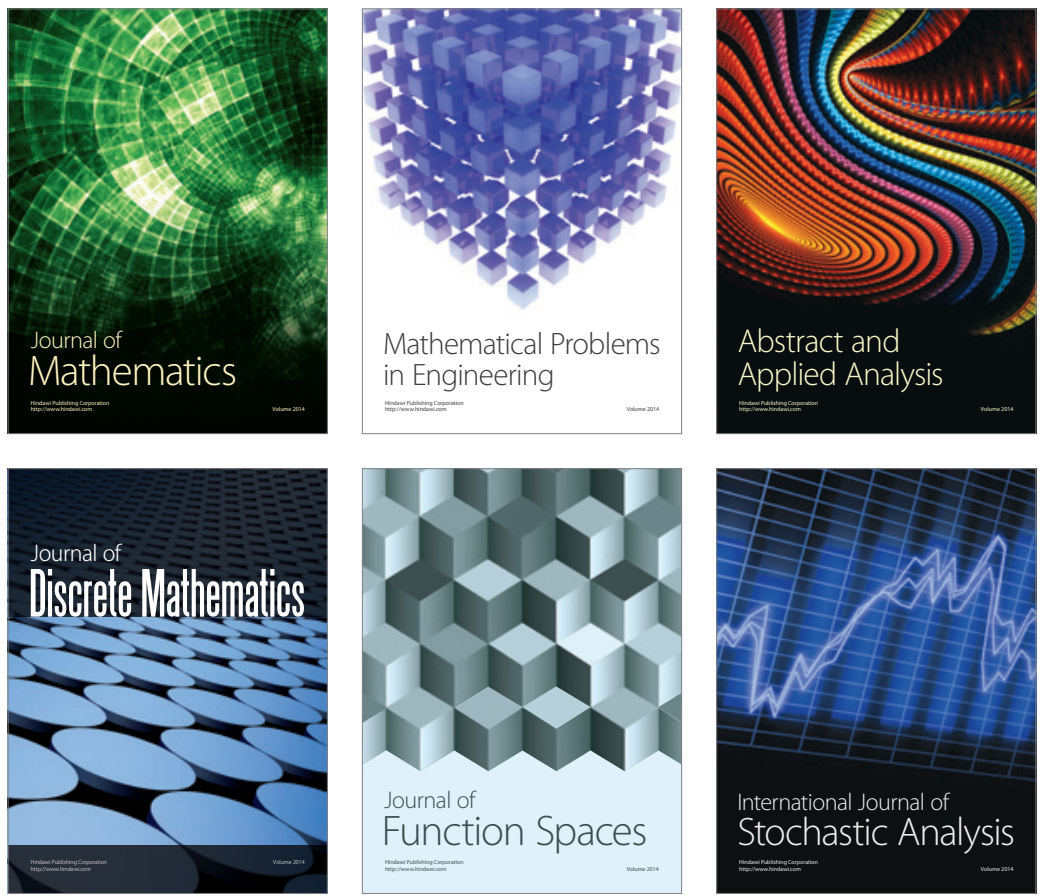

Journal of

Function Spaces

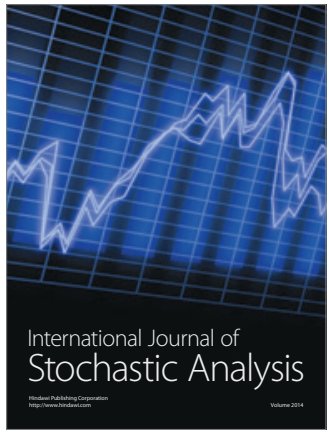

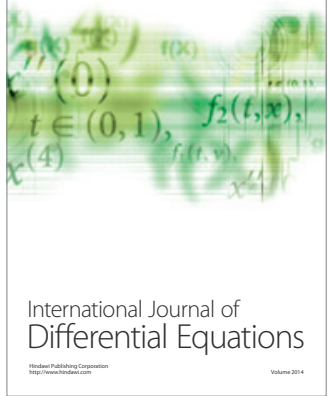
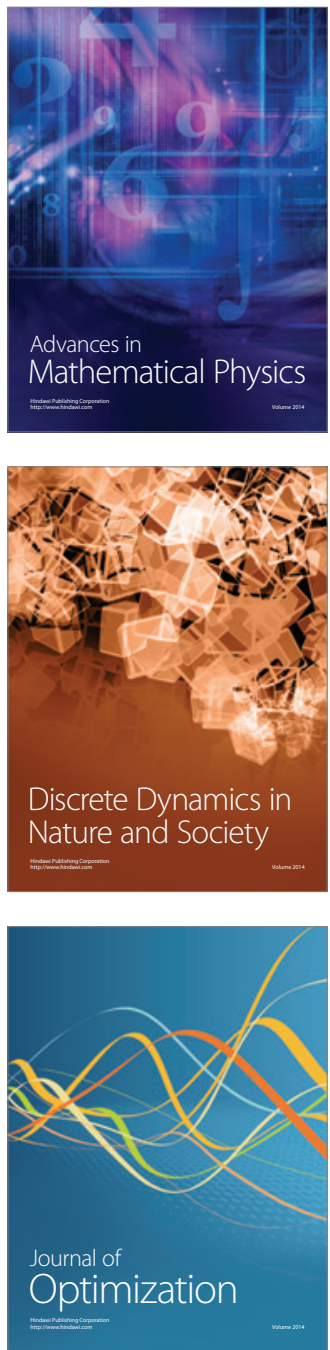